\title{
Caracterização taxonômica e fisiológica de bactérias ácido-láticas isoladas de pescado marinho
}

\author{
Taxonomic and physiological characterization of lactic acid bacteria isolated from seafood
}

\author{
Francine $\mathrm{POFFO}^{1}$, Marcus Adonai Castro da SILVA ${ }^{1 *}$
}

\begin{abstract}
Resumo
Bactérias ácido-láticas (BAL) constituem um grupo diverso, associado à produção de alimentos, incluindo fermentados de peixe. Por meio de processos fermentativos, é possível obter produtos mais saborosos e saudáveis. Estas bactérias também são importantes na medicina por suas atividades probióticas. Neste contexto, nove linhagens de bactérias ácido-láticas foram isoladas de sardinha e guaivira. Destas, duas linhagens foram caracterizadas fisiologicamente, juntamente com Leuconostoc mesenteroides ATCC8293. Lactobacillus homohiochii F3 apresentou ótimo crescimento a $40{ }^{\circ} \mathrm{C}$, diferente de Lactobacillus intestinalis $\mathrm{G} 1$ e Leuconostoc mesenteroides ATCC8293, que tiveram ótimo crescimento a $30^{\circ} \mathrm{C}$. Em relação à tolerância ao $\mathrm{NaCl}$, L. homohiochii $\mathrm{F} 3$ e L. mesenteroides ATCC8293 toleraram uma concentração de $5 \%$ de $\mathrm{NaCl}$ no meio. A espécie L. intestinalis G1 tolerou uma concentração de 7,5\%, podendo ser considerada mais halotolerante que as demais espécies. L. mesenteroides ATCC8293, por causa do aumento da taxa de crescimento, pode ser considerada levemente halofílica. Na presença de concentrações não ótimas de $\mathrm{NaCl}$, a adição de solutos orgânicos foi eficaz na restauração do balanço osmótico das células.

Palavras-chave: Lactobacillus; peixes marinhos; solutos compativeis.
\end{abstract}

\begin{abstract}
Lactic acid bacteria constitute a diversified group associated with the production of food, including fermented fishes. Through fermentative processes, it is possible to obtain several healthy and tasty products. Those bacteria are also important in medicine due to their probiotic activities. In this context, nine lactic acid bacteria were isolated from sardine and leatherjacket fish. Among them, two lineages, and the reference strain Leuconostoc mesenteroides ATCC8293 were physiologically characterized. Lactobacillus homohiochii F3 grew optimally at $40{ }^{\circ} \mathrm{C}$, differently from Lactobacillus intestinalis G1 and Leuconostoc mesenteroides ATCC8293 that grew optimally at $30{ }^{\circ} \mathrm{C}$. With regard to $\mathrm{NaCl}$ tolerance, L. homohiochii F3 and L. mesenteroides ATCC8293 grew in media containing 5\% NaCl. Lactobacillus intestinalis G1 grew in media containing $7.5 \% \mathrm{NaCl}$ and can be considered more halotolerant than the other species. L. mesenteroides ATCC8293 can be considered slightly halophilic. In non-optimal $\mathrm{NaCl}$ concentrations, the addition of organic solutes to the culture media was effective in restoring the osmotic balance of the bacteria.
\end{abstract}

Keywords: Lactobacillus; marine fishes; compatible solutes.

\section{Introdução}

A fermentação dos produtos da pesca é uma prática muito antiga e particularmente difundida na Europa e na Ásia. Alguns exemplos: os Titbits e Galffelbitars, fabricados na Noruega e na Suécia, e o Paak o Mam Chão e o Plaa-som, consumidos no Camboja e na Tailândia, respectivamente (PALUDAN-MULLER et al., 2002). Pescado fermentado também pode ser denominado silagem de pescado, com uso para ração animal, visando o reaproveitamento de resíduos gerados pelas indústrias de pescado (AQUARONE et al., 2001).

Entre os micro-organismos associados com a produção de pescado fermentado, as bactérias ácido-láticas desempenham um papel fundamental, pois são capazes de alterar, de forma favorável, a textura e o sabor destes; inibir o desenvolvimento de organismos prejudiciais à saúde, e evitar a deterioração precoce dos produtos. Além do efeito de preservação das bactérias ácido-láticas, acredita-se que sua presença nos alimentos possa ter efeito probiótico, pela produção de ácidos orgânicos e bacteriocinas (MARTINIS; SANTAROSA; FREITAS, 2003).

As bactérias ácido-láticas são caracterizadas como Gram-positivas, geralmente não móveis, não esporuladas, catalase negativas e produtoras de ácido lático, como o maior ou único produto fermentativo do metabolismo. Os principais gêneros são: Streptococcus, Lactobacillus, Leuconostoc e Lactococcus.

Para que a fermentação dos alimentos seja eficaz e livre de contaminações, as bactérias ácido-láticas devem ser utilizadas como culturas iniciadoras, nas quais são inicialmente isoladas, cultivadas e posteriormente introduzidas no alimento que se queira fermentar. Por outro lado, alimentos fermentados espontaneamente, como a maioria dos produtos de pescado, sem a utilização de culturas iniciadoras, apresentam uma microflora

${ }^{1}$ Laboratório de microbiologia aplicada, Universidade do Vale do Itajaí - Univali, Rua Uruguai, 458, CEP 88302-202, Itajaí, SC, Brasil, E-mail: marcus.silva@univali.br ${ }^{*}$ Corresponding author 
ineficiente e incontrolável, gerando produtos pouco seguros e de baixa qualidade (GIRAFFA, 2003).

O estudo da fisiologia das BAL é importante para promover um entendimento mais amplo dos mecanismos de adaptação empregados por estes micro-organismos, em relação aos processos de fermentação do pescado e de outros alimentos. Dessa forma, estes organismos podem ser utilizados de forma mais eficiente na indústria alimentícia, obtendo-se assim um maior controle do processo de produção e, consequentemente, da qualidade do produto final. Neste contexto, o presente trabalho teve como objetivos o isolamento e a identificação de bactérias ácido-láticas isoladas de amostras de pescado marinho, bem como a caracterização fisiológica dos isolados obtidos e uma linhagem referência.

\section{Material e métodos}

\subsection{Coleta e preparo das amostras}

As amostras de peixes utilizadas para a realização do experimento foram: sardinha (Sardina pilchardus), guaivira (Oligoplites saliens), merluza (Merluccius sp.) e abrótea (Urophycis brasiliensis). Os espécimes foram coletados em uma rede de arrasto e fornecidos pelo Oceanógrafo José Maria da Conceição, MSc.

As vísceras dos peixes (aproximadamente $10 \mathrm{~g}$ ) foram cortadas e transferidas para um Erlenmeyer $(250 \mathrm{~mL})$, respectivo para cada uma das espécies amostradas, contendo $90 \mathrm{~mL}$ de solução salina ( $\mathrm{NaCl}$ a 0,85\%). Em seguida, a mistura (solução salina + pescado) foi triturada, obtendo-se uma amostra homogênea (AMERICAN..., 1992).

Isolamento de Bactérias Ácido-láticas de Pescado Marinho. $\mathrm{O}$ isolamento das bactérias foi realizado pelo método de isolamento direto em meio sólido. Primeiramente, foram preparadas diluições decimais seriadas até $10^{-3}$, em solução salina estéril $(0,85 \%)$, a partir das amostras homogeneizadas. Em seguida, 0,1 mL de cada uma das amostras diluídas e brutas foram inoculados em placas de Petri contendo meio ágar BHI, pela técnica de espalhamento em placas. Por fim, as placas foram transferidas para uma estufa à temperatura de $30{ }^{\circ} \mathrm{C}$, incubadas em anaerobiose por sete dias. Após a incubação, colônias de diferentes morfologias foram repicadas em placas de Petri contendo meio ágar BHI, para o seu isolamento. Este procedimento foi repetido até a obtenção de culturas puras (AMERICAN..., 1992; RINGO; GATESOUPE, 1997), que foram conservadas em meio MRS sólido.

\subsection{Caracterização fenotípica das bactérias isoladas}

As bactérias isoladas foram identificadas utilizando-se critérios morfológicos, bioquímicos e diferentes condições de crescimento. As características morfológicas estudadas foram: reação de Gram, morfologia e arranjo celular, e motilidade. $\mathrm{O}$ crescimento dos organismos foi verificado nas seguintes condições: $15^{\circ} \mathrm{C}$ e $45^{\circ} \mathrm{C}$, e a uma concentração de $6,5 \%$ de $\mathrm{NaCl}$. Os testes bioquímicos realizados foram: produção de catalase (com $\mathrm{H}_{2} \mathrm{O}_{2}$ a 3\%); degradação da arginina em meio para descarboxilase de Moeller; fermentação e produção de gás da glicose em meio MRS contendo tubos de Durham invertidos, e produção de ácido a partir dos carboidratos lactose, celobiose, manitol, maltose, manose, raffinose, galactose, xilose e frutose (CARR; CHIll; MAIDA, 2002; SMIBERT; KRIEG, 1994). A partir do resultado destes testes, os organismos foram identificados segundo Carr, Chill e Maida (2002).

\subsection{Caracterização fisiológica dos isolados obtidos}

Determinação das temperaturas ótima, máxima e mínima de crescimento. Para determinação dos valores de temperatura ótimo, máximo e mínimo de crescimento, as bactérias foram cultivadas em frascos de Erlenmeyer $(500 \mathrm{~mL})$, contendo $250 \mathrm{~mL}$ de meio MRS, às temperaturas de $5^{\circ} \mathrm{C}, 10^{\circ} \mathrm{C}, 15^{\circ} \mathrm{C}, 20^{\circ} \mathrm{C}, 30^{\circ} \mathrm{C}$, $40^{\circ} \mathrm{C}, 45^{\circ} \mathrm{Ce} 50^{\circ} \mathrm{C}$. O inóculo foi feito a partir de uma pré-cultura em meio MSR, incubada por 24 horas, a $30^{\circ} \mathrm{C}$. Após a inoculação das bactérias, os frascos referentes às temperaturas de $5^{\circ} \mathrm{Ca} 20^{\circ} \mathrm{C}$ foram transferidos para estufa refrigerada com circulação de ar, enquanto que os frascos referentes às temperaturas de $30{ }^{\circ} \mathrm{C}$ a $50{ }^{\circ} \mathrm{C}$ foram colocados em banho-maria. Em nenhum destes procedimentos, as culturas estavam sob agitação. $\mathrm{O}$ tempo de incubação, em todos os casos, foi de 48 horas. $\mathrm{O}$ valor máximo de temperatura correspondeu ao maior valor deste parâmetro no qual o organismo apresenta crescimento. Da mesma forma, o valor mínimo de temperatura correspondeu ao menor valor no qual se observa crescimento. $\mathrm{O}$ valor ótimo de temperatura para o crescimento de um determinado organismo foi determinado a partir da taxa de crescimento deste organismo em cada um dos valores de temperatura. $\mathrm{O}$ valor ótimo de temperatura correspondeu ao valor no qual a taxa de crescimento é máxima. Para a obtenção dos valores de taxa de crescimento, a densidade óptica $(605 \mathrm{~nm})$ das culturas foi determinada ao longo do experimento, como medida de crescimento. Estas determinações foram feitas de uma em uma hora, durante as primeiras três horas, e de duas em duas horas, durante cinco horas após a inoculação, incluindo o tempo inicial. A partir das medições de densidade óptica, a taxa de crescimento foi calculada, como descrito a seguir. Este procedimento foi repetido três vezes (BREZNAK; COSTILOW, 1994).

Determinação das concentrações ótimas, máximas e mínimas de sódio para o crescimento. Para determinação das concentrações de sódio ótima, máxima e mínima de crescimento, as bactérias foram cultivadas em frascos de Erlenmeyer $(500 \mathrm{~mL})$, contendo $250 \mathrm{~mL}$ de meio MRS, nas seguintes concentrações de sódio: $0 \%, 2,5 \%, 5 \%, 7,5 \%, 10 \%$, $15 \%$. O inóculo foi feito a partir de uma pré-cultura em meio MRS, incubada por 48 horas, a $30{ }^{\circ} \mathrm{C}$. Após a inoculação, os frascos foram transferidos para uma estufa à temperatura de $30{ }^{\circ} \mathrm{C}$. As concentrações ótimas, máximas e mínimas foram determinadas da mesma forma descrita para a temperatura. Este procedimento foi repetido três vezes (BOWMAN, 2001).

Efeito de Solutos Compatíveis Sobre o Crescimento de Bactérias Ácido-láticas na Presença do Sódio. Para a determinação do efeito de solutos compatíveis sobre o crescimento das bactérias isoladas na presença do sódio, estas foram cultivadas em frascos de Erlenmeyer $(500 \mathrm{~mL})$, contendo $250 \mathrm{~mL}$ de meio MRS e solutos compatíveis (ROBERT et al., 
2000), nas seguintes concentrações de sódio: $0 \%, 2,5 \%, 5 \%, 7,5 \%$, $10 \%$ e $15 \%$. O inóculo foi feito a partir de uma pré-cultura em meio MRS, incubada por 48 horas, a $30^{\circ} \mathrm{C}$. Após a inoculação, os frascos foram transferidos para uma estufa à temperatura de $30^{\circ} \mathrm{C}$. As concentrações ótima, máxima e mínima foram determinadas da mesma forma descrita para a temperatura. Este procedimento foi repetido três vezes.

Calculo da taxa de crescimento. A taxa de crescimento foi calculada por meio de regressão linear dos valores logaritimizados $\left(\log _{10}\right)$ de densidade óptica em relação ao tempo. A partir do coeficiente angular obtido, a taxa de crescimento foi calculada pela fórmula $K=a^{\star} 2,303$, sendo $K=$ taxa de crescimento e $\mathrm{a}=$ coeficiente angular (WHITE, 2000).

\subsection{Análise dos dados}

Os dados foram armazenados e analisados graficamente, em planilhas do software Microsoft Excel, e analisados estatisticamente com ANOVA, e pelo teste de Tukey para múltiplas amostras, utilizando o software Statistica ${ }^{\oplus}$.

\section{Resultados e discussão}

Por meio do processo de isolamento, foram obtidas bactérias ácido-láticas de apenas duas espécies, sardinha e guaivira. Os organismos isolados foram identificados em três espécies distintas, representadas por seis, uma e duas linhagens (Tabela 1).

Avaliando-se os relatos fornecidos na literatura, pode-se observar que o gênero Lactobacillus é comumente relatado como flora abundante em peixes (RINGO et al., 1997). Entretanto, as espécies descritas de Lactobacillus são distintas daquelas identificadas no presente trabalho. Por exemplo, RINGO;
GATESOUPE, (1997) isolaram Lactobacillus plantarum e Leuconostoc mesenteroides da região gastrointestinal de truta ártica (Salvelinus alpinus). Assim como estes autores, outros também relatam a presença de gêneros distintos de bactérias ácido-láticas em peixes, como, por exemplo, Carnobacterium e Streptococcus, sendo este último como patógeno de trutas, enguias e outras espécies (RINGO et al., 1997). No presente estudo, duas espécies de bactérias ácidoláticas foram encontradas na amostra de Sardinha, L. farciminis S1 e L. homohiochii F3. Já na amostra de Guaivira, apenas L. intestinalis G1 foi identificado. Esta diferença de espécies de micro-organismos nos diferentes peixes utilizados, como amostras, pode estar relacionada a diversos fatores, como a própria espécie de peixe utilizada, a localidade de captura dos peixes e a sua base alimentar, que tende a ser determinante para a composição da flora gastrintestinal destes (RINGO et al., 1997).

Crescimento em diferentes temperaturas. Foi analisado o crescimento em diferentes temperaturas de duas linhagens derivadas do isolamento a partir do pescado marinho, L. homohiochii F3 e L. intestinalis G1, e de uma linhagem referência, L. mesenteroides ATCC8293. O micro-organismo L. homohiochii $\mathrm{F} 3$ apresentou crescimento mínimo à temperatura de $5^{\circ} \mathrm{C}$, melhorando significativamente seu crescimento a partir de $20^{\circ} \mathrm{C}$. O crescimento máximo e ótimo ocorreu a $40^{\circ} \mathrm{C}$, cessando a temperaturas acima deste valor (Tabela 2 ). Os valores das taxas de crescimento para as diferentes temperaturas apresentaram diferença significativa entre si ( $\mathrm{p} \geq 0,000159)$. O micro-organismo L. intestinalis $\mathrm{G} 1$ apresentou crescimento similar a $5{ }^{\circ} \mathrm{C}$ e a $10{ }^{\circ} \mathrm{C}$, porém com diferença estatisticamente significante entre si $(\mathrm{p}=0,000160)$. $\mathrm{O}$ crescimento ótimo foi verificado a $30^{\circ} \mathrm{C}$, apresentando valores de taxa de crescimento nesta temperatura com diferença significativa em termos estatísticos, em relação com

Tabela 1. Linhagens de bactérias ácido-láticas isoladas do pescado marinho.

\begin{tabular}{|c|c|c|c|}
\hline Amostras de peixes & Data de isolamento & Código da linhagem & Espécies \\
\hline Sardinha & $26 / 11 / 2004$ & $\mathrm{~F} 1$ & Lactobacillus homohiochii \\
\hline Sardinha & $26 / 11 / 2004$ & F3 & Lactobacillus homohiochii \\
\hline Sardinha & $26 / 11 / 2004$ & $\mathrm{~F} 4$ & Lactobacillus homohiochii \\
\hline Sardinha & $26 / 11 / 2004$ & F7 & Lactobacillus homohiochii \\
\hline Sardinha & $26 / 11 / 2004$ & F8 & Lactobacillus homohiochii \\
\hline Sardinha & $26 / 11 / 2004$ & F10 & Lactobacillus homohiochii \\
\hline Sardinha & $12 / 08 / 2004$ & $\mathrm{~S} 1$ & Lactobacillus farciminis \\
\hline Guaivira & $12 / 08 / 2004$ & G1 & Lactobacillus intestinalis \\
\hline Guaivira & $12 / 08 / 2004$ & G2 & Lactobacillus intestinalis \\
\hline
\end{tabular}

Tabela 2. Médias das taxas de crescimento $(\mathrm{K})$ de três linhagens de bactérias ácido-láticas em diferentes temperaturas.

\begin{tabular}{ccc}
\hline Temperaturas & & Taxa de crescimento \\
\cline { 2 - 4 } & $\begin{array}{c}\text { Lactobacillus } \\
\text { homohiochii } \mathrm{F} 3\end{array}$ & $\begin{array}{c}\text { Lactobacillus } \\
\text { intestinalis G1 }\end{array}$ \\
\hline $5^{\circ} \mathrm{C}$ & 0,04 & 0,06 \\
$10^{\circ} \mathrm{C}$ & 0,08 & 0,06 \\
$15^{\circ} \mathrm{C}$ & 0,13 & 0,12 \\
$20^{\circ} \mathrm{C}$ & 0,31 & 0,33 \\
$30^{\circ} \mathrm{C}$ & 0,50 & 0,41 \\
$40^{\circ} \mathrm{C}$ & 0,64 & 0,30 \\
$45^{\circ} \mathrm{C}$ & - & 0,17 \\
\hline
\end{tabular}


as demais temperaturas testadas ( $\mathrm{p} \geq 0,000159)$, exceto a $10^{\circ} \mathrm{C}$. $\mathrm{O}$ crescimento cessou a temperaturas acima de $40^{\circ} \mathrm{C}$ (Tabela 2). Em contraste, pode-se verificar que L. mesenteroides ATCC8293 não apresentou crescimento a temperaturas abaixo de $15^{\circ} \mathrm{C}$ e acima de $30^{\circ} \mathrm{C}$. Seu crescimento máximo e ótimo foi verificado a $30{ }^{\circ} \mathrm{C}$ (Tabela 2), apresentando, estatisticamente, diferença de crescimento nas temperaturas de $15^{\circ} \mathrm{C}$ e $30^{\circ} \mathrm{C}(\mathrm{p}=0,006449)$, fato ausente nas temperaturas de $15^{\circ} \mathrm{C}$ e $20^{\circ} \mathrm{C}$.

Semelhante ao presente trabalho, Ishikawaa et al. (2003) estudaram a taxa de crescimento de bactérias ácido-láticas isoladas de organismos marinhos e verificaram que a temperatura ótima de crescimento das amostras foi entre $37^{\circ} \mathrm{C}$ e $40{ }^{\circ} \mathrm{C}$. A taxa de crescimento para as diferentes temperaturas da linhagem M13-2 (Marinilactibacillus psychrotolerans) foi de 0,36 a $25^{\circ} \mathrm{C}$; 0,52 a $30{ }^{\circ} \mathrm{C} ; 0,60$ a $37^{\circ} \mathrm{C} ; 0,42$ a $40{ }^{\circ} \mathrm{C}$, e 0,02 a $42.5^{\circ} \mathrm{C}$, tendo uma taxa de crescimento máxima observada à temperatura de $37^{\circ} \mathrm{C}$. Em comparação com os micro-organismos estudados, L. homohiochii F3 pode ser considerado mais termotolerante que Marinilactibacillus psychrotoleran, tendo maior taxa de crescimento a $40^{\circ} \mathrm{C}$.

O crescimento em diferentes temperaturas por bactérias do gênero Lactobacillus também foi estudado por outros autores. A linhagem Lactobacillus casei ATCC4646, por exemplo, teve seu crescimento restrito ao intervalo de $32{ }^{\circ} \mathrm{C}$ a $45{ }^{\circ} \mathrm{C}$ (MA; MARQUIS, 1997). Esta diferença pode estar relacionada com os locais de isolamento destes micro-organismos, pois Lactobacillus casei ATCC4646 é originado de cáries dentárias, um ambiente com temperaturas mais elevadas e mais constantes que o ambiente marinho.

Crescimento em diferentes concentrações salinas na presença de solutos orgânicos. O crescimento das três linhagens também foi analisado na presença de diferentes porcentagens de $\mathrm{NaCl}$ e de três solutos orgânicos testados individualmente. O micro-organismo L. homohiochii F3, na ausência de solutos orgânicos, tolerou apenas até $2,5 \%$ de sal no meio, apresentando máximo crescimento na ausência de sal. Nas demais concentrações salinas, não houve crescimento celular. Pode-se verificar que a adição dos solutos orgânicos no meio permitiu que o micro-organismo adquirisse capacidade de crescer até $5 \%$ de sal. Note-se que os valores das taxas de crescimento na ausência de solutos e na presença dos mesmos, mostraram-se estatisticamente diferentes entre si ( $\mathrm{p}=0,000227)$ (Tabela 3).

O micro-organismo L. intestinalis G1, na ausência de solutos orgânicos, no meio, cresceu até 7,5\% de sal. Para

Tabela 3. Médias das taxas de crescimento (K) de Lactobacillus homohiochii F3 em diferentes concentrações salinas, na ausência e na presença de três solutos orgânicos distintos.

\begin{tabular}{rcccc}
\hline \multirow{2}{*}{$\begin{array}{c}\text { Concentração } \\
\text { salina }\end{array}$} & \multicolumn{5}{c}{ Taxa de crescimento } \\
\cline { 2 - 5 } & Sem solutos & Trealose & Glicina betaína & Sacarose \\
\hline $0 \%$ & 0,42 & 0,46 & 0,46 & 0,35 \\
$2,50 \%$ & 0,31 & 0,41 & 0,31 & 0,55 \\
$5 \%$ & - & 0,28 & 0,09 & - \\
$7,50 \%$ & - & - & - & - \\
$10 \%$ & - & - & - & - \\
$15 \%$ & - & - & - & - \\
\hline
\end{tabular}

L. intestinalis G1, a presença dos diferentes solutos orgânicos, no meio, não foi eficiente para promover um aumento da tolerância ao sal nas concentrações 10\% e 15\% (Tabela 4). Porém, ao se realizar o teste estatístico, todas as taxas de crescimento calculadas na ausência e na presença de solutos compatíveis, foram significativamente diferentes entre si $(p=0,000231)$.

Em meio ausente de solutos orgânicos, o micro-organismo L. mesenteroides ATCC 8293 cresceu até 2,5\% de sal, podendo-se verificar, nesta concentração, uma maior taxa de crescimento quando comparado a $0 \%$ de sal. $\mathrm{O}$ soluto glicina-betaína não foi eficiente para este micro-organismo a ponto de permitir com que tolerasse maiores concentrações salinas. Já os solutos trealose e sacarose favoreceram para que o micro-organismo crescesse também a uma concentração de 5\%, sendo a maior taxa de crescimento verificada na presença de sacarose (Tabela 5). Estatisticamente, as taxas de crescimento obtidas foram diferentes significativamente entre si nos diferentes casos testados ( $p \geq 0,000227$ ), exceto os valores calculados para a sacarose a 0 e $2,5 \%$ de $\mathrm{NaCl}$, que não apresentaram diferença estatística $(\mathrm{p}>0,05)$.

Segundo os dados fornecidos na literatura, o gênero Lactobacillus seria um dos mais halotolerantes entre as BAL, tendo sido relatado crescimento na presença de até $10 \%$ de $\mathrm{NaCl}$ (Paludan-Muller et al., 2002). Algumas espécies de Lactobacillus também apresentam o crescimento limitado a baixas concentrações de $\mathrm{NaCl}$, como, por exemplo, Lactobacillus sakei (4\%) (MARCEAU et al., 2004), Lactobacillus delbrueckii (3,48\%) e Lactobacillus bulgaricus (1,74\%) (HUTKINS; EllEFSoN; KASHKET, 1987). Ishikawa et al. (2003), ao calcularem a taxa de crescimento para a espécie Marinilactibacillus psychrotolerans em diferentes concentrações salinas, verificaram que essas taxas

Tabela 4. Médias das taxas de crescimento (K) de Lactobacillus intestinalis G1 em diferentes concentrações salinas, na ausência e na presença de três solutos orgânicos distintos.

\begin{tabular}{rcccc}
\hline \multirow{2}{*}{$\begin{array}{c}\text { Concentração } \\
\text { salina }\end{array}$} & \multicolumn{4}{c}{ Taxa de crescimento } \\
\cline { 2 - 5 } & Sem solutos & Trealose & Glicina betaína & Sacarose \\
\hline $0 \%$ & 0,44 & 0,43 & 0,42 & 0,48 \\
$2,50 \%$ & 0,29 & 0,35 & 0,31 & 0,35 \\
$5 \%$ & 0,25 & 0,22 & 0,15 & 0,21 \\
$7,50 \%$ & 0,14 & 0,13 & 0,08 & 0,11 \\
$10 \%$ & - & - & - & - \\
$15 \%$ & - & - & - & - \\
\hline
\end{tabular}

Tabela 5. Médias das taxas de crescimento(K) de Leuconostocmesenteroides ATCC8293 em diferentes concentrações salinas, na ausência e na presença de três solutos orgânicos distintos.

\begin{tabular}{rcccc}
\hline \multirow{2}{*}{$\begin{array}{c}\text { Concentração } \\
\text { salina }\end{array}$} & \multicolumn{4}{c}{ Taxa de crescimento } \\
\cline { 2 - 5 } & Sem solutos & Trealose & Glicina betaína & Sacarose \\
\hline $0 \%$ & 0,06 & 0,26 & 0,21 & 0,11 \\
$2,50 \%$ & 0,15 & & 0,25 & 0,12 \\
$5 \%$ & - & 0,15 & - & 0,22 \\
$7,50 \%$ & - & - & - & - \\
$10 \%$ & - & - & - & - \\
$15 \%$ & - & - & - & - \\
\hline
\end{tabular}


aumentavam com o aumento da concentração de sal. Fato observado também neste trabalho, para os micro-organismos L. mesenteroides ATCC8293, que também utilizaram o $\mathrm{NaCl}$ para seu crescimento, num primeiro momento, podendo estes ser considerados halofílicos.

Além do sal, outros compostos podem causar estresse celular, como, por exemplo, os açúcares. Estes, em altas concentrações no meio, causam um estresse osmótico, porém de forma bem mais leve que os sais, uma vez que promovem um rápido equilíbrio entre os meios intra e extracelular. Em contradição, segundo Glaasker et al. (1998), as células teriam baixa afinidade pelos açúcares, o que os tornaria pouco eficientes na osmoproteção. Tal fato que não foi observado no presente trabalho, no qual a sacarose e a trealose tiveram efeitos benéficos na regulação osmótica. O soluto trealose foi capaz de permitir que L. homohiochii F3 e L. mesenteroides ATCC8293 conseguissem crescer até uma concentração de $5 \%$ de $\mathrm{NaCl}$, e a sacarose reduziu eficientemente a inibição de crescimento de L. mesenteroides ATCC8293 ocasionado pelo $\mathrm{NaCl}$, permitindo que este crescesse também até uma concentração de $5 \%$ de sal no meio; esses fatos não foram observados na ausência destes solutos.

\section{Conclusões}

Dentre as linhagens isoladas, pode-se verificar que o gênero Lactobacillus é flora dominante nos peixes analisados (Sardinha e Guaivira), em relação ao grupo das BAL. Em decorrência dos testes fisiológicos de temperatura, L. intestinalis G1 e L. homohiochii F3, quando comparados com L. mesenteroides ATCC8293, mostraram-se mais termotolerantes. Para os testes de salinidade, L. homohiochii F3 e L. intestinalis G1 podem ser ditos halotolerantes, quando comparados com L. mesenteroides ATCC8293, que se mostrou levemente halofílico. Por fim, mostra-se importante a presença dos solutos orgânicos glicina betaína, trealose e sacarose; estes podem ser considerados compostos eficazes no processo de osmoproteção para as linhagens estudadas, uma vez que foram responsáveis pela regulação osmótica em condições adversas.

\section{Referências bibliográficas}

AMERICAN PUBLIC HEALTH ASSOCIATION - APHA. Compendium of Methods for the Microbiological Examination of Foods. 3th ed. Washington: APHA, 1992.

AQUARONE, E. et al. Biotecnologia Industrial: Biotecnologia na Produção de Alimentos. São Paulo: Edgard Blucher Ltda, 2001.

BOWMAN, J. P. Methods for psycrophilic bacteria. In: PAUL, J. H. Marine Microbiology. London: Academic Press, 2001. cap. 29, p. 591-614. (Methods in Microbiology, v. 30).

BREZNAK, J. A.; COSTILOW, R. N. Physicochemical factors in growth. In: GERHARDT, P. et al. Methods for General and Molecular Bacteriology. Washington: ASM Press, 1994. cap. 6, p. 137-154.
CARR, F.; CHILL, D.; MAIDA, N. The lactic acid bacteria: a literature survey. Critical Reviews in Microbiology, v. 28, n. 4, p. 281-370, 2002. PMid:12546196. http://dx.doi.org/10.1080/1040-840291046759

GIRAFFA, G. Studying the dynamics of microbial populations during food fermentation. FEMS Microbiology Reviews, v. 28, p. 251-260, 2003. PMid:15109787. http://dx.doi.org/10.1016/j. femsre.2003.10.005

GLAASKER, E.; TJAN, F. S. B.; TER STEEG, P. F.; KONINGS, W. N.; POOLMAN, B. Physiological response of Lactobacillus plantarum to salt and nonelectrolyte stress. Journal of Bacteriology, v. 180, n. 17, 1998.

HUTKINS, R. W.; ELLEFSON, W. L.; KASHKET, E. R. Betaine transport imparts osmotolerance on a strain of Lactobacillus acidophilus. Applied and Environmental Microbiology, v. 53, n. 10, p. 2275-2281, 1987.

ISHIKAWA, M. et al. Marinilactibacillus psychrotolerans gen. Nov. Sp. Nov., a halophilic and alkaliphilic marine lactic acid bacterium isolated from marine organisms in temperate and subtropical areas of Japan. International Journal of Systematic and Evolutionary Microbiology, v. 53, p. 711-720, 2003. http://dx.doi.org/10.1099/ ijs.0.02446-0

MA, Y.; MARQUIS, R. E. Thermophysiology of Streptococcus mutans and related lactic-acid bacteria. Antonie van Leeuwenhooek, v. 72, p. 91-100, 1997. PMid:9298187. http://dx.doi. org/10.1023/A:1000290426248

MARCEAU, A. et al. Evidence of involvement of at least six proteins in adaptation of Lactobacillus sakei to cold temperatures and addition of $\mathrm{NaCl}$. Apllied and Environmental Microbiology, v. 70, n. 12, p. 7260-7268, 2004.

MARTINIS, E. C. P.; SANTAROSA, P. R.; FREITAS, F. Z. Caracterização preliminar de bacteriocinas produzidas por seis cepas de bactérias láticas isoladas de produtos cárneos embalados a vácuo. Ciência e Tecnologia dos Alimentos, v. 23, n. 2, p. 195-199, 2003.

PALUDAN-MULLER, C. et al. Fermentation and microflora of Plaa-som, a Thai fermented fish product prepared with different salt concentrations. International Journal of Food Microbiology, v. 73, p. 61-70, 2002. http://dx.doi.org/10.1016/S0168-1605(01)00688-2

RINGO, E.; GATESOUPE, F. Lactic acid bacteria in fish: a review. Aquaculture, v. 160, p. 177-203, 1997. http://dx.doi.org/10.1016/ S0044-8486(97)00299-8

ROBERT, H. et al. Glycine betaine, carnitine, and choline enhance salinity tolerance and prevent the accumulation of sodium to a level inhibiting growth of Tetragenococcus halophila. Applied and Environmental Microbiology, v. 66, n. 2, p. 509-517, 2000. PMid:10653711. PMCid:91856. http://dx.doi.org/10.1128/ AEM.66.2.509-517.2000

SMIBERT, R. M.; KRIEG, E N. R. Phenotypic characterization. In: GERHARDT, P. et al. Methods for General and Molecular Bacteriology. Washington: ASM Press, 1994. cap. 25, p. 607-654.

WHITE, D. The Physiology and Biochemistry of Prokaryotes. Oxford: Oxford University Press, 2000. 